\title{
Nordion retreats from defamation lawsuit
}

Published at www.cmaj.ca on Aug. 13

$\mathrm{M}$ DS Nordion Inc. has quietly walked away from a \$2-million lawsuit it launched against an outspoken American academic who accused it of misleading the Canadian government about the impact of failing to quickly restart the troubled National Research Universal (NRU) reactor in Chalk River, Ontario, after its 2007 shutdown.

The May 2008 lawsuit was launched against Alan Kuperman, an assistant professor with the University of Texas LBJ School of Public Affairs at the University of Texas Austin.

In the aftermath of the NRU shutdown, Kuperman was widely quoted in several media outlets as being critical of Nordion for exaggerated claims about the extent to which the health of patients in need of diagnostic tests would be put at risk because of the shutdown. (www.cmaj.ca/cgi/doi/10.1503/cmaj.080 154), Nordion claimed that Kuperman's remarks were defamatory.

Nordion declined to be interviewed about its rationale for walking away from the lawsuit. But Tamara Benjamin, the firm's vice-president of communications, wrote in an email that "we fully respect individuals' rights to articulate political and policy views. We think that's appropriate. Where we become concerned is when factually inaccurate and potentially damaging statements are made. We filed a lawsuit because we believed the defendant was making defamatory and untrue statements about MDS Nordion. Such commentary is not appropriate. It was important for that to stop and it did."

Kuperman was "shocked" by the \$2-million lawsuit. "It was me against a multi-billion dollar corporation and it was pretty scary."

The firm also sent Kuperman a letter asking for a retraction and a public apology. It went so far as to include the text of a retraction and apology, asking that Kuperman publicly admit his statements "were unfounded" and retract statements "without reservation and sincerely apologize to MDS Nordion for having made them."

Kuperman says he filed a statement of defence, in which he reiterated his concerns that Nordion was misleading the federal government when it sought to have the NRU quickly restarted.

Subsequent events demonstrated that other reactors could help to offset a

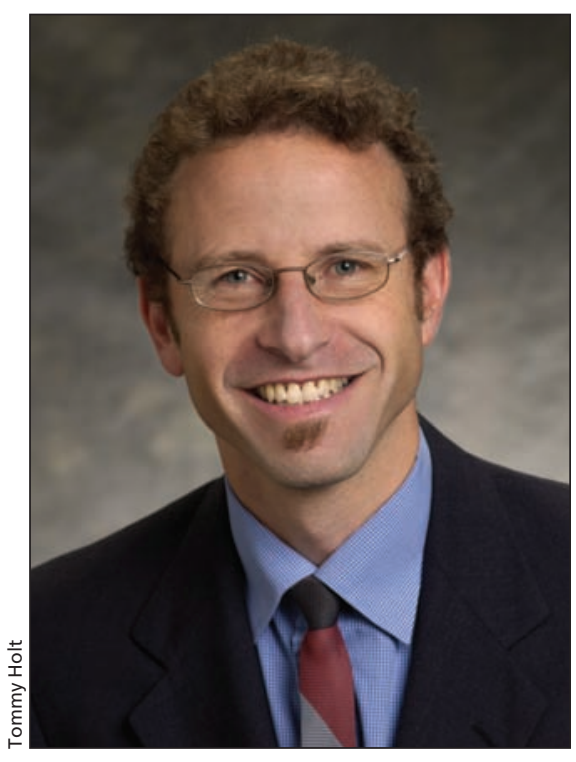

"It was me against a multi-billion dollar corporation and it was pretty scary," say Alan Kuperman, an assistant professor with the University of Texas LBJ School of Public Affairs at the University of Texas Austin

supply shortfall, he adds. "The fact is that it (NRU reactor) has been down for more than a year and while it has affected the supply of isotopes and inconvenienced patients, it did not create the kind of problems" that Nordion claimed would ensue.

Nordion has continued to resist efforts by the other major medical isotope producers to coordinate reactor maintenance, re-enforcing the idea that the company is preoccupied with market share and not with stabilizing the global supply of isotopes, Kuperman adds. "What Nordion really feared in 2007 was not the impact [the reactor shutdown] would have on patients, but the impact it would have on Nordion."

A European isotope supplier has previously accused Nordion of thwarting a 1999 effort to create a global back-up plan to mitigate the effects of a disruption to the world's medical isotope supply, (www.cmaj.ca/cgi/doi/10.1503/ cmaj.080256).

The supply situation now appears much less dismal.

"A better supply structure" has evolved, says Dr. Christopher O’Brien, president of the Ontario Association of Nuclear Medicine. "The peaks and troughs now are not as bad."

"There has been a more concerted effort by producers to coordinate reactor shutdowns to ease the impact on supply, while additional capacity has been found in smaller research reactors that traditionally did not produce medical isotopes," O'Brien says. Moreover, there has been a shift toward newer diagnostic technologies, such as positron emission tomography, which some believe are as accurate as nuclear tests.

More problematic is determining how patients fared during the shortage, O'Brien says, adding that reports have indicated there was as much as a $20 \%$ decrease in the number of diagnostic referrals in the past two years, while many patients were referred for nonnuclear tests.

"We know there were patients who either didn't have tests done or they had other types of tests done," he says. "But the impact on a patient by patient basis? We don't know that and I don't think we'll ever know that."

But Canada fared better than countries such as Japan or regions like Central and South America, O'Brien says, adding that some countries have even benefited from the protracted isotope brouhaha. Australia, for example, brought new reactors online and has now become almost isotope self-sufficient. Dan Lett, Winnipeg, Man.

DOI:10.1503/cmaj.109-3336 